\title{
Discussion of Ormond
}

\section{Who Determines What Story is Told? Silenced Voices and Narratives of Marginalisation}

\author{
Mere Kēpa \\ Nga Pae o te Maramatanga/The Centre of Research Excellence for Maori Development and Advancement \\ hosted by the University of Auckland, New Zealand
}

\begin{abstract}
$\mathrm{D}$ evelopment or transformation can be understood as an active process. The process has confronted and mobilised Maori people since our ancestors departed Hawai'iki to settle Aotearoa-New Zealand. In coming to understand the land the ancestors called 'Aotearoa', we changed. And as we changed, our internal and external symbionts and parasites also changed with us. Maori people have endured disease, climatic change, natural disasters, human made disasters, political disasters, economic disasters, educational disasters, and linguistic disasters for nearly two centuries. And as the indigenous people of Aotearoa we continue to be changed by and to change the prevailing assumptions on development (and sustainability) to become healthier and more imaginative people.
\end{abstract}

Following on this tradition, Dr Adreanne Ormond critiques the assumption that the narratives of the young descendants of Rongomaiwahine and Ngati Kahungunu and the prevailing 'outsider' societal group are juxtaposed in present day Aotearoa. Like other books and texts on the same subject, the article emphasises the conscious or unconscious process of alienating Maori people from our land and sea, silencing our language, and hope by the narratives of the prevailing outsider societal group. Thus, a broader and deeper framework to apprehend societal development and economic advancement of Maori, by Maori in the 21st century is necessitated.

Having related the research findings of others as well as those of her doctoral thesis to the youth dwelling in her community at Mahia peninsula, Ormond is well qualified to address and encounter the range of cultural, health, economic, educational and political silences presented in her manuscript. The daily lives of the Mahisians have provided Ormond with a rich context to inform researchers, scholars and teachers of the range of controversial and exigent beliefs and practices that have, and continue to marginalise the youth. At the same time, Ormond's article invites us to consider a diverse rather than a microscopic methodology to apprehend the Mahisian youths most persistent hardships with regard to health, tertiary education, employment and income, and a sense of continual hope to change, to become healthier women and men, to become wiser people.

Part of the hope conveyed in Ormond's work is her framework or discourse of dominant and marginalised narratives, a refreshing transformation to the dominant societal group's individualistic and consumerist ethos. More, the diverse and critical framework would enable other Maori people - say, the academics and researchers working voluntarily on resource management in the tribal territories - to voice candidly our views on the tendency of the dominant outsider group to pathologise those who live on the margins and to suckle off the assumption of rural bliss for their individual development and economic advancement. Such a consideration will be my task in the discussion that follows.

\section{'Suckling off Rural Bliss'}

For nearly two centuries foreign experts have been coming from Europe and the USA to Aotearoa. They 
have looked at Aotearoa, Maori people's language, beliefs, knowledge, information and practices through a telescope of their own making. The indigenous perspective here is that examining Aotearoa and Maori people with a telescope, microscope or magnifying glass results in a loss of scent and tactile senses while it accentuates the view that the land and the people are historically and societally unblemished. The foreigners have established countless linguistic anthropological, archaeological and most recently genetic terminologies, categories and descriptions about Maori people, our land and our sea. On the foreigners' telescopic framework of understanding development, language is an instrument that deadens the emotional, spiritual, and the historically contextualised aspects of culture. Ignoring the senses embedded in the language is to ignore whose culture is being privileged. Expressed simply, the framework ignores whose story is being told!

Concepts of sustainability are ingrained in both the outsider and the Maori people's narratives. In brief, sustainability focuses on the capability or potential of natural resources to provide people's requirements of food and fuel (Chetham, 1998, p. 17). Nonetheless, two assumptions have arisen, one supporting the balancing of developmental and environmental interests in order to attain sustainable management and the other advocating an environmental bottom line (Chetham, 1998, p. 16). Part of the despair for Maori people is that individualism, consumerism and the bottom line interest obviously play important roles in managing resources in the coastal places where we live (perhaps not for much longer). The burgeoning tourist industry; seclusion, peace and relaxation in an exclusive residential estate; fossil fuel and mineral exploration, and metal and sand extraction all contribute or arguably constitute a view of our sea and our land as a global resource ready for individual consumption. Understanding development as a neutral 'tool' in the hands of individual developers, companies, government agencies at central, regional and local levels is to misapprehend the way development shapes everyday living by Maori.

In its many guises, development silences Maori people's relationship with our land and our sea, and the very language we use when we are confronted by the developers. In other words, there has been a silencing of one of the different ways development could be understood and the resources sustained. In the main, development is assumed to be neutral or objective (Irwin, 2005, p. 1) but it can also be argued that development silences, alienates and marginalises Maori people, our land and our sea. It would seem reasonable to say that Ormond, myself, Irwin and Chetham argue for a more diverse set of views on development, which engages with the societal, cultural and environmental conditions that shape, constrain, and are in fragile co-existence with assumptions that govern the prevailing discourse. This is the concern of Maori people working in resource management and who raise cultural, not merely economic and individualistic understandings, on development and sustainability.

\section{The Tool Wielding Animal}

Development is a specifically human activity but has an impact far larger than any individual, any community, or any generation. In my territory for example, I would tend to characterise the prevailing outsider societal group as the 'tool wielding animal' (Irwin, 2005, pp. 2-3), which suggests that individuals survey, measure, manipulate and control the natural environment through instruments. In contrast to the Maori discourse of relating heaven, nature and earth, it might be more useful to understand the dominant societal group as being wielded by development as a 'means to occur, or come into being' (Irwin, 2005, p. 3 ). It would be fair to suggest that the tool wielding animal plays a pivotal role in the present crescendo of development in my coastal territory in Aotearoa.

In her article, Ormond (2007) warns Maori people that, 'mainstream New Zealand society duplicitously gains societal and economic power from the minority societal group while deflecting the connection between dominant societal group privilege and minority societal group knowledge'. The indigenous point being made is that understanding development as a neutral tool in the hands of the prevailing outsider societal group is to misapprehend the way development shapes Maori people's reality as an underclass, our culture primitive and unfit for the modern world. Indeed, the tool-wielding animal rather than strengthening Maori people's interrelatedness with our land and sea scours our seabed of its sand and silences the ancient marine life. Another typical illustration of the deflection is the driver of the machine that unearths our sacred mountains for metal and exhumes our ancestors at the same time. Further examples of this vulnerability are the humanmade port that has smothered the ancient fishing grounds; the gated estate, the cafe, the restaurant, and the shopping mall that have suffocated the ancient gardens. Other cases in point are the saw mill, the oil refinery and the chemical plant that choke the air with hazardous toxins; the logging truck and the bulk liquid carrier that contaminate the flora and fauna subsisting along the roadside. What is left of nature, the wildlife, live out fragile lives of continual survival. In short, development misshapes not only the capability or potential of natural resources to provide the local Maori people's requirements of food and fuel but our societal and economic advancement as well. 
And, all this human activity is ignored by the narrow focus of the outsider's telescopic framework.

The outsider societal group's discourse dominating development in my territory would, then, make development 'more of a private act' tending towards fortifying the tool-wielding animal as the 'conduit of language' (Irwin, 2005, p. 6). Influenced by Fine, Ormond elucidates the idea in the following way:

'... although both societal groups can and do speak through either discourse, the dominant societal group shapes both discourses so that they represent and protect their societal group interests more than the interests of the indigenous community'. (Ormond, 2008, p. 34)

Ironically, though, Ormond's outsider and Maori discourses bring forth the dynamic interplay between language and habitual thought. That is, the framework enables Maori people to talk back to the dominant discourse of 'Cartesian individualist rationality' (Irwin, 2005, p. 6), thus enabling our voice to be heard. In other words, rather than highlighting only the rational packaging of individualism and consumerism governing the language and accepted wisdom to development grounded on use value, the framework accentuates the Maori discourse of interrelatedness between heaven, nature and the earth. In this critical discourse of development and language the people, environmental sustainability and culture are no longer silenced.

Nothing is neutral. Ormond's discourse of dominant and marginalised narratives draws attention to the fact that when closely scrutinised the prevailing discourse that distances or separates people, heaven and nature falls short in many ways. The shortfall is that the body exists somewhere 'it' is the eye that observes the unblemished land and sea through the telescope, for instance. It is the stare behind the infrared wavelength that maps out the unblemished land. It is the hand that propels the machine to dig up our seabed and our ancient tribal estate. It is the hand that disinters the ancestors and that troubles the relationship between the Maori and the outsider societal group. The absence of the body is a myth! Besides, the land is not merely physically located, it is ethereal! The mind that conceptualises Maori as the underclass, our culture primitive and unfit for the modern world is obscured but it is the voice that diminishes the emotional, corporeal, and societally contextualised qualities of culture. Ormond has recharged the discourse of development and sustainability, so it hums with questions about meaning, context and power relations, in doing so the environment and the Maori people's relationship to it are brought to the forefront.

\section{Closing Remarks}

To put all of this within the introduction with which I began this discussion, there remains that assumption that development has confronted and mobilised Maori people since our ancestors settled Aotearoa. In the 21 st century, the argument remains that development has shifted our phenomenological sensibility, radically changed Maori people's relationship with our land and our sea from a sublime understanding of nature, heaven and the earth to a discourse that regards everything as a resource for (ab)use. Ormond makes a convincing argument that, on the whole, dynamic societal relationships tend to reinforce the telescopic or the outsider societal group's discourse. This discourse assumes that tools are an efficient development system. It does not smell, taste and feel while it accentuates the view of that which is unseen. The problem of the obscured way of the dominant group's thinking that is embedded in tools also operates at the level of language and forms the relationship between them, the Maori people and the planet. Ormond has put the case that the Maori people can and must talk back to the instrumental agent of development to open up and awaken our meanings of our relative importance (or lack thereof) and the unique significance of the planet we inhabit as well.

The strength of Ormond's article, therefore, remains the comprehensive and critical discourse framing her argument and that in turn has provided me the opportunity to address and discuss the powerful and vital issues confronting and mobilising societal development and economic advancement of Maori, by Maori.

\section{References}

Camara, P. (2000). Going public. Levels of racism: A theoretic framework and a gardner's tale. American Journal of Public Health, 90(8), 1212-1215.

Chetham, J. (1998). Kaitiakitanga and the Resource Management Act: Tangata whenua, participation and morality. Unpublished master's thesis, University of Auckland, Auckland, New Zealand.

Irwin, R. (2005). The technology environment: Subjectivity, language and machine. International Journal of Technology and Design Education, 15(1), 1-12.

Ormond, A. (2008). The life experiences of young Maori: Voices from afar. Journal of Pacific Rim Psychology, 2, 33-42.

Reynolds, P. (2004). Ngā Puni Whakapiri: Indigenous struggle and genetic engineering. Unpublished doctoral dissertation, Simon Fraser University, Vancouver, Canada. 